Marquette University

e-Publications@Marquette

Chemistry Faculty Research and Publications

Chemistry, Department of

9-24-2018

\title{
A Synthetic Model of the Nonheme Iron-Superoxo Intermediate of Cysteine Dioxygenase
}

Anne A. Fischer

Marquette University

Sergey V. Lindeman

Marquette University, sergey.lindeman@marquette.edu

Adam T. Fiedler

Marquette University, adam.fiedler@marquette.edu

Accepted version. Chemical Communications, Vol. 54, (2018): 11344-11347. DOI. (C) 2018 The Royal Society of Chemistry. Used with permission. 
Marquette University

\title{
e-Publications@Marquette
}

\section{Chemistry Faculty Research and Publications/College of Arts and Sciences}

This paper is NOT THE PUBLISHED VERSION; but the author's final, peer-reviewed manuscript. The published version may be accessed by following the link in the citation below.

Chemical Communications, Vol. 54, No. 80 (September 2018): 11344-11347. DOI. This article is (C) The Royal Society of Chemistry and permission has been granted for this version to appear in ePublications@Marquette. The Royal Society of Chemistry does not grant permission for this article to be further copied/distributed or hosted elsewhere without the express permission from The Royal Society of Chemistry.

\section{A Synthetic Model of the Nonheme Iron- superoxo Intermediate of Cysteine Dioxygenase ${ }^{\dagger}$}

\author{
Anne A. Fischer, Sergey V. Lindeman and Adam T. Fiedler * \\ Department of Chemistry, Marquette University, 1414 W. Clybourn St., Milwaukee, WI 53233, USA. E- \\ mail: adam.fiedler@marquette.edu
}

Received 1st August 2018, Accepted 17th September 2018 First published on 24th September 2018

\begin{abstract}
A nonheme Fe(II) complex (1) that models substrate-bound cysteine dioxygenase (CDO) reacts with $\mathrm{O}_{2}$ at $-80{ }^{\circ} \mathrm{C}$ to yield a purple intermediate (2). Analysis with spectroscopic and computational methods determined that 2 features a thiolate-ligated Fe(III) center bound to a superoxide radical, mimicking the putative structure of a key CDO intermediate.
\end{abstract}

The metabolism of amino acids and related biomolecules is often dependent upon mononuclear nonheme iron enzymes (NHIEs) that activate $\mathrm{O}_{2}$ for the oxidation of organic substrates. ${ }^{1}$ An example with significance for human health is cysteine dioxygenase (CDO), a NHIE that transforms exogenous L-cysteine (Cys) into cysteine sulfinic acid (Cys-

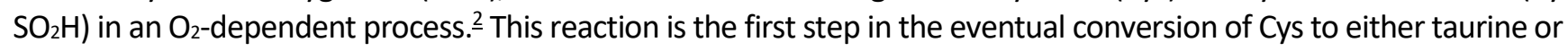
sulfate. ${ }^{-}$A thiol dioxygenation reaction is also catalyzed by cysteamine dioxygenase (ADO) in the degradation pathway 
of coenzyme A. ${ }^{4} \mathrm{CDO}$ and $\mathrm{ADO}$ activities are essential for avoiding elevated cellular levels of free thiols, which have been linked to neurological conditions ${ }^{-5}$ and autoimmune disorders. ${ }^{6}$ The active site of CDO consists of an Fe(II) center facially coordinated by three histidine residues.? X-ray studies revealed that the deprotonated Cys substrate binds to the Fe(II) center in a bidentate N,S-mode (Scheme 1), 8 and a similar substrate-bound geometry is likely adopted by ADO.

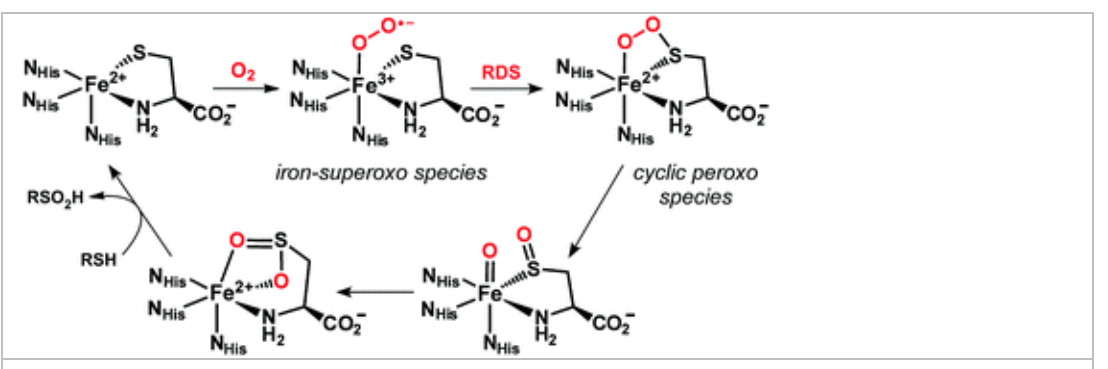

Scheme 1 Proposed CDO mechanism (RDS = rate-determining step).

In the proposed mechanism, the sequential binding of thiolate and $\mathrm{O}_{2}$ yields a six-coordinate iron(III)superoxide adduct. - As required of iron enzymes that catalyze four-electron substrate oxidations, $\underline{10}$ the iron(III)superoxo species of CDO/ADO initiates oxidation of the coordinated substrate, in this case through generation of a putative $\mathrm{Fe}$ "-O-O-S intermediate (Scheme 1). DFT studies suggest that formation of this cyclic peroxo intermediate is the rate-determining step in the catalytic cycle. $\underline{\underline{11}}$ Thus, the iron(III)-superoxo species occupies the pivotal position in the catalytic mechanisms of thiol dioxygenases. Yet it has proven difficult to detect this intermediate in studies of CDO and related model complexes. Nonheme iron-superoxo species exhibit short lifetimes even at reduced temperatures, and their EPR-silent nature and lack of distinct absorption features hinder spectroscopic characterization. Due to these factors, only four synthetic nonheme iron-superoxo complexes have been reported thus far (three mononuclear and one dinuclear)..$\underline{12}$

Recently, we described the synthesis and reactivity of CDO and ADO models that employed a tris(imidazol-2yl)phosphine ligand to mimic the 3-histidine triad. $\frac{13}{}$ Although exposure of these functional models to $\mathrm{O}_{2}$ yields the corresponding sulfinic acid products, intermediates of the dioxygenation reaction were not detected. Since then, we surmised that it might be possible to extend the lifetime of reactive species by preparing CDO models with alternative substrates that are similar to, but not identical with, the native substrate. Moreover, our experience with cobaltsubstituted CDO models,,$\underline{14}$ as well as a report from the Hikichi group,,$\underline{12 b}$ suggested that the hydrotris(3,5dimethylpyrazolyl)borate ligand ( $\mathrm{Tp}^{\mathrm{Me}}$ ) facilitates formation of metal-superoxo species due to its small steric profile. With these ideas in mind, we prepared the complex, [Fe(Tp $\left.\left.{ }^{\mathrm{Me}}\right)(2-\mathrm{ATP})\right](\mathbf{1})$, where 2-ATP is 2-aminothiophenolate (Fig. 1). The monoanionic 2-ATP ligand was selected based on biochemical studies by Pierce and coworkers that suggest it binds to the Fe(III) center of CDO in a manner analogous to Cys. $\frac{15}{}$ Here we describe the $\mathrm{O}_{2}$ reactivity of complex 1 and provide spectroscopic evidence for the formation of a mononuclear iron-superoxo intermediate at low temperature.

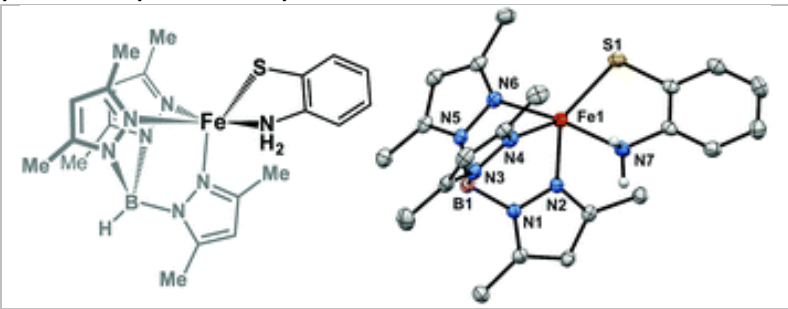

Fig. 1 Schematic drawing (left) and X-ray crystal structure (right) of [Fe(Tp $\left.\left.{ }^{\mathrm{Me} 2}\right)(2-\mathrm{ATP})\right](\mathbf{1})$. Selected bond distances $(\AA)$ and at 2.3107(4), Fe1-N2 2.0746(12), Fe1-N4 2.0817(12), Fe1-N6 2.1843(12), Fe1-N7 2.2776(13), S1-Fe1-N2 121.83(4), S1-Fe1171.75(4).

Complex 1 is generated by treatment of an iron(II) acetate precursor, [ $\mathrm{Fe}^{\prime \prime}\left(\mathrm{Tp}^{\mathrm{Me}}\right)(\mathrm{OAc})$, with the sodium salt of 2-ATP in $\mathrm{CH}_{3} \mathrm{CN}$. The complex can also be prepared, albeit in lower yield, by direct reaction of equimolar amounts of $\mathrm{Fe}(\mathrm{OTf})_{2}, \mathrm{~K}\left(\mathrm{Tp}^{\mathrm{Me} 2}\right)$, 2-aminothiophenol, and NaOMe. The UV-vis absorption spectrum of 1 in THF exhibits two weak features at 560 and $920 \mathrm{~nm}$ with molar absorptivities $\left(\varepsilon_{\mathrm{M}}\right)$ near $100 \mathrm{M}^{-1} \mathrm{~cm}^{-1}$ (Fig. 2). Light yellow crystals suitable for crystallographic analysis were grown by slow evaporation of solvent. The resulting X-ray structure, shown in Fig. 1, reveals a mononuclear, five-coordinate Fe(II) complex that lies midway between idealized square pyramidal and 
trigonal bipyramidal geometries ( $\tau$-value of 0.52 ). The average Fe- $\mathrm{N}_{T p}$ bond length of $2.11 \AA$ is typical of high-spin Fe(II) complexes with $\mathrm{Tp}^{\mathrm{Me} 2}$ ligands, and the Fe-S bond length of $2.31 \AA$ is virtually identical to values observed for CDO models with aliphatic thiolates..$\frac{13,16}{}$

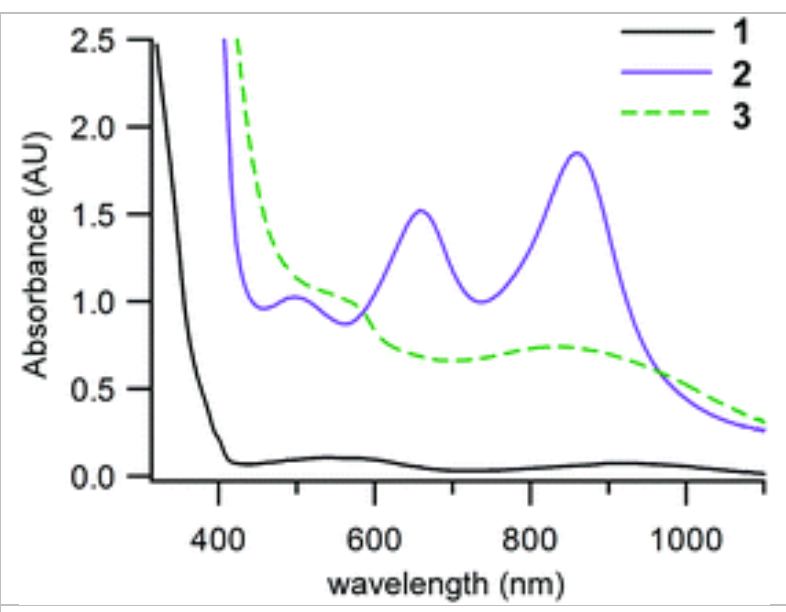

Fig. 2 Electronic absorption spectra of $\mathbf{1}, \mathbf{2}$, and $\mathbf{3}(0.84 \mathrm{mM})$ in THF at $-80^{\circ} \mathrm{C}$.

Exposure of complex 1 to $\mathrm{O}_{2}$ at low temperature $\left(-80^{\circ} \mathrm{C}\right)$ generates a purple chromophore (2) that features three absorption bands at $490\left(\varepsilon_{\mathrm{M}}=1200\right), 655(1800)$, and $860 \mathrm{~nm}(2200)$, as shown in Fig. 2. This EPR-silent intermediate decays at $-80^{\circ} \mathrm{C}$ with a half-life of 10 minutes, eventually yielding a greenish EPR-active species (3) with a broad absorption band centered at $830 \mathrm{~nm}$ (the EPR data are shown in Fig. S1, ESI + ). The reaction with $\mathrm{O}_{2}$ is irreversible, as bubbling argon gas through the solution at $-80^{\circ} \mathrm{C}$ fails to regenerate 1 . Species $\mathbf{2}$ is not observed when the $\mathrm{O}_{2}$ reaction is performed at room temperature; instead, complex $\mathbf{1}$ converts directly to $\mathbf{3}$. A survey of solvents determined that $\mathbf{2}$ is only generated in THF and 2-methyltetrahydrofuran (MeTHF). The glassy nature of frozen MeTHF made it possible to examine 2 with magnetic circular dichroism (MCD) spectroscopy at low temperatures (4-25 K). The MCD bands, which correspond to those observed in the absorption spectrum, display temperature-dependent intensities arising from C-term behavior (Fig. S2, ESI + ), which confirms that $\mathbf{2}$ is a paramagnetic species. Furthermore, variable-temperature variable-field MCD data collected at $885 \mathrm{~nm}$ provided a set of "nested" magnetization curves (Fig. S3, ESI†) characteristic of a species with $S \geq 1 .{ }^{17}$

Resonance Raman ( $r R$ ) spectra of intermediate 2 were collected in multiple solvents (THF, THF- $d_{8}$, and MeTHF) using $501.7 \mathrm{~nm}$ laser excitation. As shown in Fig. 3a, the spectra of $\mathbf{2}$ in THF and THF- $d_{8}$ exhibit peaks at 1105 and 1135 $\mathrm{cm}^{-1}$, respectively, that are absent in samples prepared with ${ }^{18} \mathrm{O}_{2}$. We also examined samples prepared by either exposing 1 to $\mathrm{O}_{2}$ at room temperature or warming/refreezing samples of $\mathbf{2}$. The resulting $r R$ spectra are devoid of nonsolvent features in the relevant region (Fig. S4, ESI + ), proving that the observed vibrations arise from $\mathbf{2}$ and not a decay product like 3. As summarized in Table 1 , frequencies between 1100 and $1200 \mathrm{~cm}^{-1}$ are typical of $v(0-0)$ modes of $\eta^{1}$ superoxo ligands in nonheme iron complexes. While the presence of two $v(\mathrm{O}-\mathrm{O})$ vibrations could be indicative of multiple species, it is more likely that the $1105 / 1135 \mathrm{~cm}^{-1}$ pair correspond to a Fermi doublet centered near $1120 \mathrm{~cm}^{-1}$. Indeed, a Fermi doublet with a peak separation of $\sim 30 \mathrm{~cm}^{-1}$ was also observed for the $\left.v^{16} \mathrm{O}-{ }^{16} \mathrm{O}\right)$ mode of the Tp $\mathrm{Tp}^{\mathrm{Me}}$ based iron(III)-superoxo complex generated by Hikichi. $\stackrel{12 \mathrm{~b}}{ }$ Based on literature values (Table 1 ), the corresponding $v\left({ }^{18} \mathrm{O}-{ }^{18} \mathrm{O}\right)$ mode of 2 is expected to appear between 1040 and $1070 \mathrm{~cm}^{-1}$. This region is largely obscured by solvent peaks in THF and THF- $d_{8}$; however, an isotope-sensitive peak is observed at $1055 \mathrm{~cm}^{-1}$ in MeTHF (Fig. 3b). Assignment of this peak to the $v\left({ }^{18} \mathrm{O}-{ }^{18} \mathrm{O}\right)$ mode provides an ${ }^{16} \mathrm{O}_{2} /{ }^{18} \mathrm{O}_{2}$ downshift $\left(\Delta^{18} \mathrm{O}\right)$ of $65 \mathrm{~cm}^{-1}$, nearly identical to the value predicted by Hooke's law. 

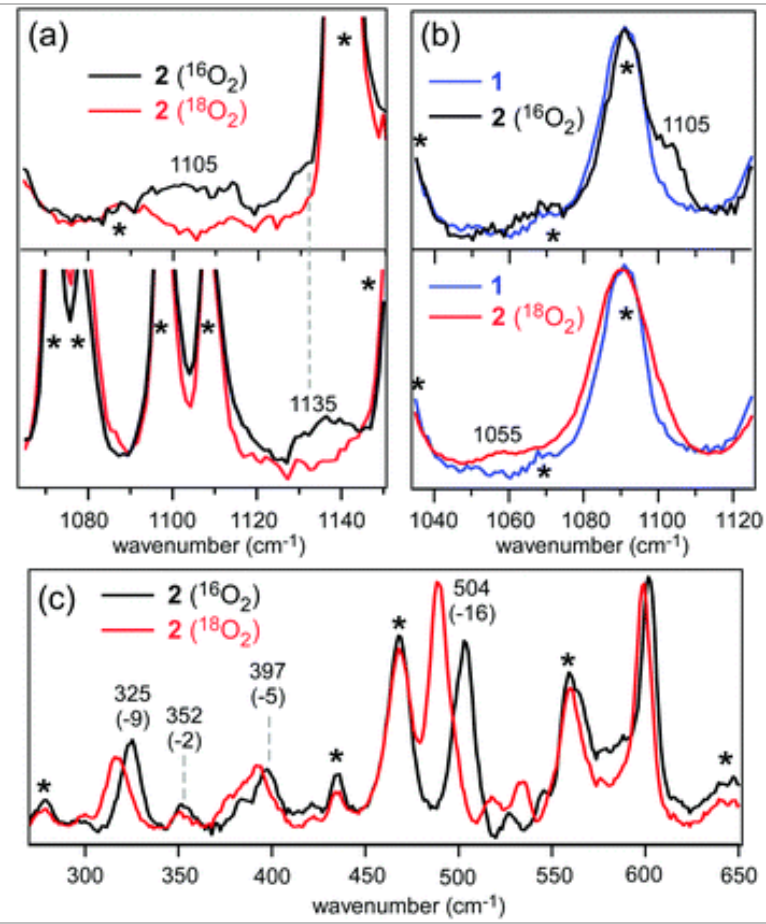

Fig. 3 rR spectra of 2 prepared with ${ }^{16} \mathrm{O}_{2}$ (black lines) or ${ }^{18} \mathrm{O}_{2}$ (red lines). Spectra were collected in either THF (a, top), THF- $d_{8}$ and c) using $501.7 \mathrm{~nm}$ laser excitation $(40 \mathrm{~mW})$. Frequencies (in cm${ }^{-1}$ ) are provided for selected peaks, with the ${ }^{16} \mathrm{O}_{2} /{ }^{18} \mathrm{O}_{2}$ iso parenthesis in part (c). Peaks marked with an asterisk $\left({ }^{*}\right)$ are due to solvent. As the $v(\mathrm{O}-\mathrm{O})$ peaks are weak compared to the the spectrum of 1 in frozen MeTHF is also shown (blue lines) in part (b).

Table 1 Frequencies and isotope shifts $\left(\right.$ in $\left.\mathrm{cm}^{-1}\right)$ reported for mononuclear iron and cobalt complexes with end-on $\left(\mathrm{\eta}^{1}\right)$ superoxo ligands ${ }^{a}$

\begin{tabular}{|c|c|c|c|c|c|}
\hline Complex & $v(0-0)$ & $\Delta\left({ }^{18} 0\right)$ & $v(\mathrm{M}-\mathrm{O})$ & $\Delta\left({ }^{18} 0\right)$ & Ref. \\
\hline$\left[\mathrm{Fe}\left(\mathrm{O}_{2}\right)\left(\mathrm{Tp}^{\mathrm{Me} 2}\right)(2-\mathrm{ATP})\right](\mathbf{2})$ & $1120^{b}$ & 65 & 504 & 16 & This work \\
\hline$\left[\mathrm{Fe}\left(\mathrm{O}_{2}\right)\left(\mathrm{Tp}^{\mathrm{Me} 2}\right)\left(\mathrm{L}^{\mathrm{ph}}\right)\right]$ & $1168^{\underline{b}}$ & 78 & 592 & 24 & $\underline{12 b}$ \\
\hline$\left[\mathrm{Fe}\left(\mathrm{O}_{2}\right)(\mathrm{BDPP})\right]$ & 1125 & 63 & n.r. & n.r. & $12 a$ \\
\hline Oxy Cyt P450cam & 1139 & 66 & 541 & 30 & $\underline{20}$ \\
\hline$\left[\mathrm{Co}\left(\mathrm{O}_{2}\right)\left(\mathrm{Tp}^{\mathrm{Me} 2}\right)\left(\mathrm{L}^{\mathrm{Ph}}\right)\right]$ & 1150 & 60 & 543 & 21 & $\underline{12 b}$ \\
\hline$\left[\mathrm{Co}\left(\mathrm{O}_{2}\right)(\mathrm{BDPP})\right]$ & 1135 & 65 & n.r. & n.r. & $\underline{21}$ \\
\hline$\left[\mathrm{Co}\left(\mathrm{O}_{2}\right)(\mathrm{py})(\right.$ salen$\left.)\right]$ & 1144 & 62 & 527 & 16 & 22 \\
\hline$\left[\mathrm{Co}\left(\mathrm{O}_{2}\right)\left(\mathrm{Tp}^{\mathrm{Me} 2}\right)(\mathrm{CysOEt})\right]$ & 1152 & 61 & n.r. & n.r. & $\underline{14}$ \\
\hline
\end{tabular}

$a$ n.r. = not reported. $b$ Average frequency of Fermi doublet peaks.

In contrast to the $v(\mathrm{O}-\mathrm{O})$ peaks, which are very weak for all nonheme iron(III)-superoxo species reported to

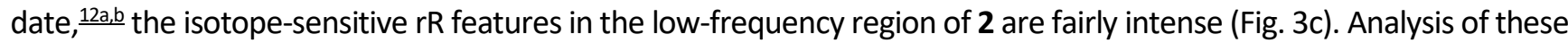
peaks further supports the proposition that $\mathbf{2}$ is an iron-superoxo species. The dominant peak at $504 \mathrm{~cm}^{-1}$ lies within the range of $470-595 \mathrm{~cm}^{-1}$ reported for $v(\mathrm{Fe}-\mathrm{O})$ frequencies of heme and nonheme iron-superoxo complexes. $\frac{12 b, 18}{}$ Although the measured $\Delta^{18} \mathrm{O}$ downshift of $16 \mathrm{~cm}^{-1}$ is smaller than the value of $22 \mathrm{~cm}^{-1}$ predicted for a pure $v(\mathrm{Fe}-\mathrm{O})$ mode, it is similar to shifts reported for related species (Table 1). A handful of weaker peaks in this region exhibit small $\Delta^{18} \mathrm{O}$-values $\left(<10 \mathrm{~cm}^{-1}\right)$, which suggests that $v(\mathrm{Fe}-\mathrm{O})$ character is distributed across multiple modes due to 
coupling. The lower-frequency peaks at $324\left(\Delta^{18} \mathrm{O}=9 \mathrm{~cm}^{-1}\right)$ and $352 \mathrm{~cm}^{-1}\left(\Delta^{18} \mathrm{O}=2 \mathrm{~cm}^{-1}\right)$ are attributed to $\delta(\mathrm{Fe}-0-0)$ and $v(\mathrm{Fe}-\mathrm{S})$ modes, respectively, based on the magnitudes of the isotope shifts and literature precedents. $\underline{12 b, 18 a, 19}$

Further insights into the geometric and electronic structures of $\mathbf{2}$ were gained through density functional theory (DFT) calculations that employed the B3LYP functional, which has proven accurate in previous studies of CDO and related model complexes. ${ }_{1,23}^{112}$ Due to exchange interactions between the unpaired electrons of $\mathrm{Fe}$ and $\mathrm{O}_{2}$, it was necessary to consider three possible spin states for this paramagnetic iron(III)-superoxo species: $S=3,2$, and 1 . The relative energies of the computational models suggest that $\mathbf{2}$ possesses a $S=2$ ground state arising from antiferromangetic coupling between the high-spin Fe(III) center and superoxide radical (details regarding the spin-state ordering are provided in the ESI + ). In the lowest-energy quintet structure (Fig. 4), the superoxo ligand forms a hydrogen bond with the $-\mathrm{NH}_{2}$ donor of 2-ATP, as evident in the $\mathrm{O} \cdots \mathrm{H}$ distance of $1.81 \AA$ and diminished Fe-O-O angle of $122^{\circ}$ (versus $134^{\circ}$ in the structure without a $\mathrm{H}$-bond). The $\mathrm{H}$-bond acts as a tether between the superoxo and 2-ATP ligand, accounting for the kinematic coupling between $v(\mathrm{Fe}-\mathrm{O}), \delta(\mathrm{Fe}-\mathrm{O}-\mathrm{O})$, and $v(\mathrm{Fe}-\mathrm{S} / \mathrm{N})$ vibrations observed in the rR data.

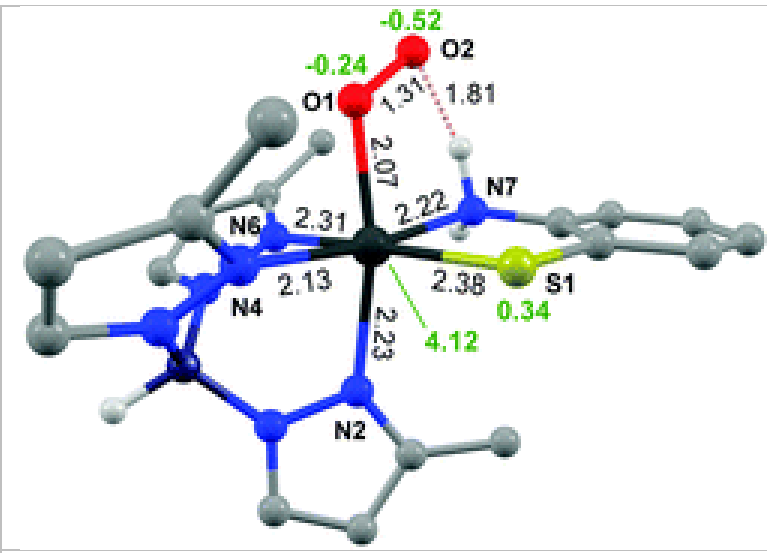

Fig. 4 DFT geometry-optimized model of $\mathbf{2}$ in the quintet $(S=2)$ state. Interatomic distances (black text) are provided in $\AA$, al populations (green text) are indicated for atoms carrying significant spin density.

In support of the veracity of our computational model, time-dependent DFT (TD-DFT) studies of $\mathbf{2}$ in the quintet state yielded a computed absorption spectrum that nicely reproduces the salient features of the experimental spectrum (Fig. S5, ESI†). The TD-DFT results were also helpful for assigning the experimental absorption bands. Like previously-reported ferric $\eta^{1}$-superoxo complexes, $\mathbf{2}$ exhibits an intense near-UV band paired with a weaker shoulder in the visible region; however, the peaks observed at 655 and $860 \mathrm{~nm}$ lack precedent in the earlier complexes with $\mathrm{N}_{5}$ or $\mathrm{N}_{3} \mathrm{O}_{2}$ supporting ligands. $\stackrel{12 a, 12 b}{ }$ TD-DFT calculations indicate that these lower-energy bands are largely due to two moderately intense $S_{\pi} \rightarrow \mathrm{Fe}(\mathrm{III})$ charge transfer (CT) transitions ( $\lambda_{\max }=669$ and $833 \mathrm{~nm}$ for the computed transitions; Fig. S5, ESI†). The experimental feature at $500 \mathrm{~nm}$ is attributed by TD-DFT to overlapping $\mathrm{S}_{\sigma} \rightarrow \mathrm{Fe}(\mathrm{III})$ and $\mathrm{O}_{2}{ }^{--} \rightarrow \mathrm{Fe}(\mathrm{III})$ $\mathrm{CT}$ transitions (the $\mathrm{S}_{\pi}$ and $\mathrm{S}_{\sigma}$ orbitals lie perpendicular and parallel to the Fe-S axis, respectively). The near-UV peak has primarily $\mathrm{O}_{2}{ }^{--} \rightarrow \mathrm{Fe}(\mathrm{III}) \mathrm{CT}$ character.

The products generated by reaction of 1 with $\mathrm{O}_{2}$ were isolated from oxygenated THF solutions, followed by analysis with ${ }^{1} \mathrm{H}$ NMR spectroscopy. These studies revealed that the sole product derived from the 2-ATP ligand is 2aminophenyl disulfide, as confirmed by comparison to spectra measured with authentic compound (Fig. S6, ESI †). The absence of observable S-oxygenated products, such as sulfinic or sulfonic acids, suggests that the decay of the ironsuperoxo species 2 does not proceed via formation of a S-O bond. Interestingly, Pierce and coworkers recently demonstrated that CDO, like 1, does not perform the $S$-dioxygenation of 2-aminothiophenol; instead, it converts this substrate to a benzothiazole compound via oxidative condensation with a primary alcohol. $\frac{15}{}$

The lack of sulfur oxygenation is due to an alternative pathway that combines dissociation of superoxide with deprotonation of the 2-ATP ligand, yielding an iron(III)-amidothiophenolate species as the ultimate product. This scenario is consistent with the $\mathrm{O}_{2}$ reactivity of related Fe(II) catecholate and $o$-aminophenolate complexes, which have been shown to undergo one-electron oxidation and loss of a proton (from the $-\mathrm{OH}$ or $-\mathrm{NH}_{2}$ donor) upon exposure to 
$\mathrm{O}_{2}$ at room temperature. $\underline{24}$ In support of this conclusion, the optical and EPR features of complex 3 closely resemble those reported by Paine et al. for ferric $o$-amidophenolate complexes. ${ }^{24 a}$ This decay pathway is the most viable option for $\mathbf{2}$ because the aromatic ring increases the acidity of the $-\mathrm{NH}_{2}$ donor of 2-ATP relative to aliphatic amines, such as Cys. In fact, our DFT studies suggest that the energetic barrier for proton transfer from 2-ATP to superoxide is lower than the barrier for formation of a $S-O$ bond by nearly $4 \mathrm{kcal} \mathrm{mol}^{-1}$ along the $S=2$ surface. Further decay of 3 yields the observed disulfide product.

To summarize, species 2 represents first report of a synthetic mononuclear iron-superoxo complex featuring a sulfur-based ligand, and the first example with direct relevance to a particular NHIE active site. We anticipate that our findings will assist in the identification of catalytic intermediates in related enzymes. To this point, Jameson et al. recently observed a short-lived species in the CDO catalytic cycle that exhibits two equally-intense CT bands at 500 and $640 \mathrm{~nm} . \stackrel{11 \mathrm{~b}}{\stackrel{ }{2}}$ The authors concluded that these features arise from either an iron-superoxo or Fe-O-O-S intermediate (Scheme 1), with the latter possibility favoured by TD-DFT calculations. While the two $\mathrm{S}_{\pi} \rightarrow$ Fe CT bands of 2 are red-shifted by $\sim 4500 \mathrm{~cm}^{-1}$ relative to the observed CDO bands, the overall similarity between the two spectra suggests that the CDO intermediate is an iron-superoxo species. This conclusion is further supported by a recent study of isopenicillin N synthase (IPNS) - another NHIE with iron-thiolate coordination - that detected an iron-superoxo intermediate with two absorption bands at 500 and $630 \mathrm{~nm} . \frac{25}{2}$ Thus, the presence of two CT bands at $\lambda_{\max } \geq 500 \mathrm{~nm}$ appears to be a general feature of thiolate-coordinated nonheme iron-superoxo species in both synthetic and enzymatic environments. Studies of the reactivity of $\mathbf{2}$ towards various substrates, as well as the synthesis of ironsuperoxo complexes related to other NHIEs, are in progress.

Financial support was received from the U.S. National Institutes of Health (1-R15-GM126522). We are grateful to Dr Thomas Brunold (University of Wisconsin) for access to MCD and rR instrumentation, and Drs James Kincaid and Yilin Liu (Marquette University) for assistance in preparing ${ }^{18} \mathrm{O}_{2}$ samples. Anne Fischer benefitted from research fellowships provided by the Denis J. O'Brien Fund and Arthur J. Schmitt Foundation of Marquette University.

\section{Conflicts of interest}

There are no conflicts to declare.

\section{Notes and references}

1. Y. Wang, J. Li and A. Liu, J. Biol. Inorg. Chem., 2017, 22, 395-405 .

2. C. A. Joseph and M. J. Maroney, Chem. Commun., 2007, 3338-3349

3. M. H. Stipanuk, C. R. Simmons, P. Andrew Karplus and J. E. Dominy, Jr., Amino Acids, 2011, 41, 91-102

4. J. E. Dominy, Jr., C. R. Simmons, L. L. Hirschberger, J. Hwang, R. M. Coloso and M. H. Stipanuk, J. Biol. Chem., 2007, 282, 25189-25198

5. R. Janaky, V. Varga, A. Hermann, P. Saransaari and S. S. Oja, Neurochem. Res., 2000, 25, 1397-1405

6. (a) C. Gordon, H. Bradley, R. H. Waring and P. Emery, Lancet, 1992, 339, 25-26 ; (b) H. Bradley, A. Gough, R. S. Sokhi, A. Hassell, R. Waring and P. Emery, J. Rheumatol., 1994, 21, 1192-1196

7. J. G. McCoy, L. J. Bailey, E. Bitto, C. A. Bingman, D. J. Aceti, B. G. Fox and G. N. Phillips, Jr., Proc. Natl. Acad. Sci. U. S. A., 2006,103, 3084-3089

8. S. Ye, X. a. Wu, L. Wei, D. Tang, P. Sun, M. Bartlam and Z. Rao, J. Biol. Chem., 2007, 282, 3391-3402

9. (a) B. S. Pierce, J. D. Gardner, L. J. Bailey, T. C. Brunold and B. G. Fox, Biochemistry, 2007, 46, 8569-8578; (b) J. A. Crawford, W. Li and B. S. Pierce, Biochemistry, 2011, 50, 10241-10253 .

10. W. A. van der Donk, C. Krebs and J. M. Bollinger, Jr., Curr. Opin. Struct. Biol., 2010, 20, 673-683

11. (a) D. Kumar, W. Thiel and S. P. de Visser, J. Am. Chem. Soc., 2011, 133, 3869-3882 ; (b) E. P. Tchesnokov, A. S. Faponle, C. G. Davies, M. G. Quesne, R. Turner, M. Fellner, R. J. Souness, S. M. Wilbanks, S. P. de Visser and G. N. L. Jameson, Chem. Commun., 2016, 52, 8814-8817.

12. (a) C.-W. Chiang, S. T. Kleespies, H. D. Stout, K. K. Meier, P.-Y. Li, E. L. Bominaar, L. Que, E. Munck and W.-Z. Lee, J. Am. Chem. Soc., 2014, 136, 10846-10849; (b) F. Oddon, Y. Chiba, J. Nakazawa, T. Ohta, T. Ogura and S. Hikichi, Angew. Chem., Int. Ed., 2015, 54, 7336-7339 ; (c) S. Hong, K. D. Sutherlin, J. Park, E. Kwon, M. A. 
Siegler, E. I. Solomon and W. Nam, Nat. Commun., 2014, 5, 5440 ; (d) X. Shan and L. Que, Proc. Natl. Acad. Sci. U.S. A., 2005, 102, 5340-5345.

13. A. A. Fischer, N. Stracey, S. V. Lindeman, T. C. Brunold and A. T. Fiedler, Inorg. Chem., 2016, 55, 11839-11853.

14. A. A. Fischer, S. V. Lindeman and A. T. Fiedler, Dalton Trans., 2017, 46, 13229-13241.

15. W. P. Morrow, S. Sardar, P. Thapa, M. S. Hossain, F. W. Foss, Jr. and B. S. Pierce, Arch. Biochem. Biophys., 2017, 631, 66-74 .

16. (a) M. Sallmann, B. Braun and C. Limberg, Chem. Commun., 2015, 51, 6785-6787 ; (b) M. Sallmann, I. Siewert, L. Fohlmeister, C. Limberg and C. Knispel, Angew. Chem., Int. Ed., 2012, 51, 2234-2237.

17. E. I. Solomon, E. G. Pavel, K. E. Loeb and C. Campochiaro, Coord. Chem. Rev., 1995, 144, 369-460 .

18. (a) L. M. Proniewicz, I. R. Paeng and K. Nakamoto, J. Am. Chem. Soc., 1991, 113, 3294-3303 ; (b) T. K. Das, M. Couture, Y. Ouellet, M. Guertin and D. L. Rousseau, Proc. Natl. Acad. Sci. U. S. A., 2001, 98, 479-484 .

19. (a) J. D. Gardner, B. S. Pierce, B. G. Fox and T. C. Brunold, Biochemistry, 2010, 49, 6033-6041 ; (b) T. Kitagawa, A. Dey, P. Lugo-Mas, J. B. Benedict, W. Kaminsky, E. I. Solomon and J. A. Kovacs, J. Am. Chem. Soc., 2006, 128, 14448-14449.

20. S. Hu, A. J. Schneider and J. R. Kincaid, J. Am. Chem. Soc., 1991, 113, 4815-4822 .

21. C.-C. Wang, H.-C. Chang, Y.-C. Lai, H. Fang, C.-C. Li, H.-K. Hsu, Z.-Y. Li, T.-S. Lin, T.-S. Kuo, F. Neese, S. Ye, Y.-W. Chiang, M.-L. Tsai, W.-F. Liaw and W.-Z. Lee, J. Am. Chem. Soc., 2016, 138, 14186-14189.

22. K. Bajdor, K. Nakamoto, H. Kanatomi and I. Murase, Inorg. Chim. Acta, 1984, 82, 207-210 .

23. M. Sallmann, S. Kumar, P. Chernev, J. Nehrkorn, A. Schnegg, D. Kumar, H. Dau, C. Limberg and S. P. de Visser, Chem. - Eur. J., 2015, 21, 7470-7479.

24. (a) B. Chakraborty, S. Bhunya, A. Paul and T. K. Paine, Inorg. Chem., 2014, 53, 4899-4912 ; (b) M. M. Bittner, S. V. Lindeman, C. V. Popescu and A. T. Fiedler, Inorg. Chem., 2014, 53, 4047-4061.

25. E. Tamanaha, B. Zhang, Y. Guo, W.-C. Chang, E. W. Barr, G. Xing, J. St. Clair, S. Ye, F. Neese, J. M. Bollinger and C. Krebs, J. Am. Chem. Soc., 2016, 138, 8862-8874 .

\section{Footnote}

† Electronic supplementary information (ESI) available: Experimental procedures, spectroscopic (EPR, $\left.r R, M C D,{ }^{1 H} N M R\right)$ data, $X$-ray crystallographic infor computed spectra. CCDC 1851803. For ESI and crystallographic data in CIF or other electronic format see DOI: 10.1039/c8cc06247a 